\title{
Identidade e produção de sentidos no discurso jornalístico: As publicações de Carta Capital sobre Jair Bolsonaro na semana do primeiro turno das eleições
}

\author{
Identidad y producción de sentidos en el discurso periodístico: Las \\ publicaciones de Carta Capital sobre Jair Bolsonaro en la semana de la \\ primera vuelta de las elecciones
}

Identity and production of meanings in journalistic discourse: The publications of Carta Capital about Jair Bolsonaro in the week of the first round of the elections

Bibiana de Moraes Dias 1

\begin{abstract}
Resumo
Esta pesquisa tem como objetivo observar, compreender e analisar a identidade e a produção de sentidos de determinado veículo de comunicação acerca de um dos candidatos à presidência nas eleições de 2018, a fim de entender como o veículo construiu seu discurso, e de que forma a linha editorial da revista escolhida para o corpus do trabalho influenciou neste discurso, procurando desta forma, identificar ideologias. Entendemos que a produção de sentidos no discurso jornalístico é um ponto muito importante a ser analisado, visto que o cenário político e jornalístico atual se apresenta rico em significações. Desta forma, o presente trabalho surge como ferramenta para compreensão de como a produção jornalística demonstra suas ideologias para abordar determinado tema, e de como estas ideologias influenciam no produto jornalístico. Para atingir e suprir os anseios de pesquisa, foi realizada uma Análise de Discurso acerca de duas matérias publicadas pela revista Carta Capital, na semana do primeiro turno das eleições para presidente do Brasil em 2018, tendo como enfoque o então candidato Jair Bolsonaro, do Partido Social Liberal (PSL). Observamos, também, ao longo da pesquisa científica, como a revista se porta perante o candidato, procurando entender seu posicionamento.
\end{abstract}

Palavras-Chave: eleições; identidade; jornalismo de revista; produção de sentidos.

\section{Resumen}

Esta investigación tiene como objetivo observar, comprender y analizar la identidad y la producción de sentidos de determinado vehículo de comunicación acerca de uno de los candidatos a la presidencia en las elecciones de 2018, a fin de entender cómo el vehículo construyó su discurso, y de qué forma la línea editorial de la revista elegida para el corpus del trabajo influenció en este discurso, buscando de esta forma, identificar ideologías. Entendemos que la producción de sentidos en el discurso periodístico es un punto muy importante a ser analizado, ya que el escenario político y periodístico actual se presenta rico en significaciones. De esta forma, el presente trabajo surge como herramienta para comprender cómo la producción periodística demuestra sus ideologías para abordar determinado tema, y de cómo estas ideologías influencian en el producto periodístico. Para alcanzar y suplir los anhelos de investigación, se realizó un Análisis de Discurso sobre dos materias publicadas por la revista Carta Capital, en la semana de la primera vuelta de las elecciones para presidente de Brasil en 2018, teniendo como enfoque el entonces candidato Jair Bolsonaro, del Partido Social Liberal (PSL). Observamos, también, a lo largo de la investigación científica, cómo la revista se porta ante el candidato, buscando entender su posicionamiento.

\footnotetext{
${ }^{1}$ Graduada em Jornalismo; Universidade Federal de Pelotas - UFPel; Pelotas, Rio Grande do Sul, Brasil; autora@email.com
} 
Palabras claves: elecciones; la identidad; periodismo de revista; producción de sentidos.

\begin{abstract}
This research aims at observing, understanding and analyzing the identity and the production of meanings of a given vehicle of communication about one of the presidential candidates in the 2018 elections, in order to understand how the vehicle constructed its discourse, and how the editorial line of the magazine chosen for the corpus of the work influenced in this discourse, seeking in this way, to identify ideologies. We understand that the production of meanings in journalistic discourse is a very important point to be analyzed, since the current political and journalistic scene presents itself rich in significations. In this way, the present work emerges as a tool to understand how the journalistic production demonstrates its ideologies to approach a certain theme, and how these ideologies influence the journalistic product. In order to achieve and fulfill the research needs, a Discourse Analysis was conducted on two articles published by Carta Capital magazine in the week of the first round of the elections for president of Brazil in 2018, focusing on the then candidate Jair Bolsonaro of the Party Social Liberal (PSL). We also observed, throughout the scientific research, how the magazine bears before the candidate, trying to understand its positioning.
\end{abstract}

Keywords: elections; identity; magazine journalism; production of meanings.

\title{
1. Introdução
}

No ano de 2018, o Brasil viveu um momento de grande decisão para o âmbito político e, consequentemente, também para as demais áreas que estão ligadas e relacionadas com a política. No mês de outubro foram realizadas as eleições para governador, deputado estadual, deputado federal, senador e presidente da república; no entanto, como de práxis, as campanhas e embates políticos se deram ao longo de todo o ano e, também, ainda no ano anterior, refletindo em debates formais e informais, opiniões, contrariedades e claro, desenvolvimento da opinião pública acerca dos candidatos que estavam pleiteando os cargos em questão.

Para concorrer à presidência da república foram inscritas as candidaturas de, em ordem alfabética: Álvaro Dias (Podemos), Cabo Daciolo (Patriota), Ciro Gomes (PDT), Fernando Haddad (PT), Geraldo Alckmin (PSDB), Guilherme Boulos (PSOL), Henrique Meirelles (MDB), Jair Bolsonaro (PSL), João Amoêdo (Novo), João Vicente Goulart (PPL), José Maria Eymael (Democracia Cristã), Marina Silva (Rede) e Vera Lúcia (PSTU). Apesar do alto número de candidaturas para o cargo, nos debates e aparições na mídia, o número de participantes caía para menos da metade, visto que os presidenciáveis com menos de cinco parlamentares no Congresso Nacional não tem obrigatoriedade de serem convidados para os debates (ficando esta decisão a cargo da emissora), e que no que se refere a convites para entrevista, acompanhamento de agenda e demais veiculações midiáticas, os veículos dão preferência aqueles candidatos com mais popularidade e maior porcentagem nas campanhas de intenção de voto. 
Desta forma, ainda em ordem alfabética, os candidatos que tiveram mais destaque e relevância no processo eleitoral foram Ciro Gomes, Fernando Haddad, Geraldo Alckmin, Jair Bolsonaro e Marina Silva, estando o candidato Jair Bolsonaro na liderança ao longo de toda a campanha eleitoral, enquanto os demais presidenciáveis alternavam suas porcentagens de intenção de voto, até as campanhas se estabilizarem apontando o segundo turno, que acabou por se concretizar: Jair Bolsonaro (PSL) e Fernando Haddad (PT) concorreriam na segunda etapa das eleições presidenciais. O pleito eleitoral foi finalizado no dia 28 de outubro, elegendo o então deputado Jair Bolsonaro como futuro presidente do Brasil.

Jair Messias Bolsonaro, 63 anos, é um político brasileiro e militar da reserva do país. É filiado ao PSL (Partido Social Liberal), foi deputado federal por vinte e sete anos pelo estado do Rio de Janeiro, representando diversos partidos ao longo de sua carreira política. Como falado acima, o agora presidente Jair Bolsonaro ocupou o topo das pesquisas desde o início do ano, quando as candidaturas ainda nem haviam sido oficializadas pelos partidos. Mas, ainda assim, o cenário pré-eleitoral foi composto por muitas forças e embates apresentando-se como muito significativo e despertando militâncias e posicionamentos por parte da população que se dividia, polarizando-se entre apoiadores inveterados do candidato e repudiadores veementes do mesmo ${ }^{2}$.

Os posicionamentos e ideias do político foram muito replicados e divulgados nos mais variados meios de comunicação, mas em principal na internet, através dos sites de rede social desde a sua pré-candidatura em 2016. Os usuários do Facebook, através de páginas e grupos que divulgavam as falas do político, começaram a engajar-se em comunidades de apoio ao militar da reserva. A repercussão das informações e falas do candidato, na maior parte das vezes feitas pelos próprios usuários, acabou por atingir cada vez mais pessoas, formando uma grande rede. Desta forma, esses grupos passam a crescer exponencialmente a partir de 2016, tomando identidade e força, característica comum dos grupos de sites de redes sociais:

\footnotetext{
Os sites de rede social, [...] podem ser compreendidos como elementos ampliadores da esfera pública que proporcionam um espaço onde, além da socialização, os atores podem expressar e reproduzir opiniões políticas e ideias que contribuem para o debate público (RECUERO, BASTOS E ZAGO, 2015, p. 35).
}

Ora, com este crescimento rápido e abundante da popularidade do político, não aumentaram apenas seus apoiadores e simpatizantes de suas ideias, mas também cresceu o

\footnotetext{
${ }^{2}$ Disponível em https://especiais.gazetadopovo.com.br/eleicoes/2018/pesquisas-eleitorais/todos/todas-aspesquisas-eleitorais/. Acesso em 20 de novembro de 2018.
} 
número de pessoas que discordava e se opunha às falas de Jair Bolsonaro, aumentando, desta forma, não só o número de seguidores do então candidato, mas também o número de haters (odiadores, em tradução literal) do mesmo.

Jair Bolsonaro apresentou, ao longo dos dois anos de campanha (desde quando começou a ganhar mais fama, em 2016, até as eleições no final de 2018), ideias que se apresentavam opostas a todas aquelas que comumente vemos nos discursos dos demais políticos brasileiros. Aos poucos, o capitão da reserva foi ficando conhecido pelas falas em que, de forma despreocupada, abordava opiniões e temas que eram (ou ainda são) bastante polêmicos.

É claro que, com todo o envolvimento da população e do meio político em relação não apenas à eleição em si, mas mais especificamente acerca do próprio então candidato Jair Bolsonaro, outras pautas que tratavam especificamente sobre o militar da reserva acabaram também fazendo parte das pautas dos veículos de comunicação, sejam eles jornais impressos, revistas, rádios, emissoras de televisão, veículos online etc,. Assim, o número de pautas que tratavam sobre o candidato foi crescendo juntamente com a popularidade do mesmo, passando também de pautas típicas do período pré-eleitoral para englobarem outros assuntos mais específicos do então candidato.

Desta forma, com a aproximação do primeiro turno do pleito eleitoral, as matérias que tinham como pauta o militar da reserva cresceram muito, visto que o então candidato continuava liderando as pesquisas e tomando distância dos demais concorrentes, apontando como praticamente certa a sua participação no segundo turno. Pudemos observar matérias que tratavam desde assuntos atuais sobre Jair Bolsonaro até algumas que traziam informações sobre seu passado como político e as coisas que já havia feito.

Tomamos como exemplo a edição do dia 3 de outubro da revista Carta Capital, na qual o veículo trazia um compilado de cinco matérias abordando as eleições que ocorreriam naquela semana e dando enfoque principal ao candidato Jair Bolsonaro, dedicando três das cinco matérias a assuntos que envolviam o político.

Desta forma, tomaremos como objeto deste estudo duas das matérias da edição supracitada da revista Carta Capital que abordam o candidato, a fim de compreendermos quais os sentidos produzidos pela revista através de seu discurso e também percebermos traços da identidade da mesma, relacionando estes pontos com a sua linha editorial e a ideologia presente nestes discursos.

\subsection{Relações identitárias e políticas em Carta Capital}


A Carta Capital é uma revista semanal, fundada em 1994 e, atualmente, conta com duas versões para assinantes: impressa e digital. Além disso, no site da revista existe uma grande variedade de matérias e artigos que podem ser lidos gratuitamente. De acordo com artigo publicado em projeto da $\mathrm{UEL}^{3}$, o diretor de redação da revista é Mino Carta, jornalista ítalo-brasileiro, nascido no ano de 1933, em Gênova, Itália. Antes de tomar a frente da Revista Carta Capital, Mino dirigiu também redações de outras importantes revistas como Quatro Rodas, o Jornal da Tarde, IstoÉ, e Veja.

A revista é distribuída pela Editora Confiança, fundada em 2001, ano em que a Carta Capital mudou sua distribuição de semanal para quinzenal. A editora é encarregada de todos os produtos do grupo Carta Capital e tem exclusividade para eles, em texto encontrado no site da própria revista, a editora é definida ${ }^{4}$ :

Além da [revista] semanal, que completa 21 anos em 2015, a empresa edita mais
dois títulos voltados para professores, Carta na Escola (para professores do Ensino
Médio) e Carta Fundamental (para docentes do Fundamental), mantém o site
CartaCapital com colunistas e blogs independentes e uma unidade produtora
audiovisual, a TV Carta. Ao longo dos anos, a editora também firmou-se como uma
das mais sólidas idealizadoras e organizadoras de eventos corporativos do Brasil,
com destaque para "As Empresas Mais Admiradas do Brasil", premiação que está
prestes a completar duas décadas de história.

O compromisso com os leitores e com a informação é, a todo momento, ressaltado nos textos de apresentação tanto da revista quanto da editora, posicionando-se como democrática e à serviço do público.

A fim de compreender quais são as relações identitárias presentes nos discursos deste veículo dedicaremos alguns parágrafos à conceituação de identidade e, mais especificamente, dando foco à identidade na pós-modernidade. Ora, compreendemos, com base em Hall (2006), a identidade como possuindo três fases e sujeitos principais, são eles o sujeito do Iluminismo, sujeito sociológico e sujeito pós-moderno. O primeiro destes é um "indivíduo totalmente centrado, unificado, dotado das capacidades de razão, de consciência e de ação" (HALL, 2006, p. 10), caracterizando um sujeito que seria unicamente alguma coisa, sem ter desvios desta identidade ou outras características que compusessem sua identidade, sendo o mesmo durante toda a sua vida. Já o sujeito sociológico é mais complexo, e tem enfoque na relação com os que o cercam, formando sua identidade através destas relações. Por fim, o sujeito pós-moderno é como o resultado dos processos que acontecem ao longo destes dois outros sujeitos, trata-se de um indivíduo que tem não apenas uma caracterização e definição, mas que porta-se e toma papéis diferentes nos diversos âmbitos de sua vida, colocando-se

\footnotetext{
${ }^{3}$ Disponível em: http://www.uel.br/projetos/trialogos/0808/0808a.htm, acesso em 22 de outubro de 2018.

${ }^{4}$ Disponível em https://www.cartacapital.com.br/editora/sobre-a-editora. Acesso em 22 de outubro de 2018.
} 
como um ser plural e diverso, típico do mundo pós-moderno em que estamos inseridos atualmente (HALL, 2006).

Assim, compreendemos que o sujeito de hoje, que vive na era pós-moderna e consome os mais variados veículos de comunicação, através de diversos meios, e dentre estes veículos está, é claro, a Carta Capital, tem características próprias e específicas. Observamos um cenário muito amplo para os dois lados: ao passo que lidamos com uma grande demanda de busca por informações, estas informações são, a todo o tempo, disparadas a nós através dos veículos de comunicação (através, principalmente, da internet).

Ora, cabe neste momento ao sujeito consumir aqueles veículos com os quais mais se aproxima e identifica, tendo como base para isso principalmente os fatores que compõem a sua identidade. Como a revista Carta Capital, apesar de ser uma revista de grande renome e popularidade no cenário brasileiro, tem uma linha editorial definida e produz matérias e reportagens dentro desta linha, acaba tendo consumidores que também se encaixam e identificam com ela.

É nesta pluralidade do indivíduo e, consequentemente, da sua personalidade e identidade, que buscaremos a análise dos discursos produzidos pela revista Carta Capital, a fim de não a delimitar a apenas uma concepção única, mas justamente compreender quais são as influências e características identitárias e significativas que o veículo exerce através de suas produções jornalísticas. Para isso, realizaremos uma Análise do Discurso, a fim de que possamos analisar detalhamentos de texto e marcas linguísticas que nos possibilitem tais interpretações.

\section{Desenvolvimento}

\subsection{Metodologia}

Como supracitado, utilizaremos como aporte teórico-metodológico para a presente pesquisa alguns conceitos da Análise de Discurso de Linha Francesa, através da qual procuraremos entender quais os sentidos construídos pela Revista Carta Capital a respeito do então candidato Jair Bolsonaro.

A Análise de Discurso tem por objetivo não apenas analisar as características textuais dadas no objeto de análise, mas compreender o que há por trás destas características e o que elas representam em seu contexto, levando em conta todo seu processo de produção. Desta forma, de acordo com Rocha e Deusdará (2005, p. 318 e 319): 
o surgimento da Análise do Discurso se caracteriza não só por uma reorientação teórica da relação entre o lingüístico e o extralingüístico, como também por uma mudança da postura do observador em face do objeto de pesquisa.

Assim, com base no que é proposto pelos conceitos da Análise de Discurso, compreendemos a linguagem não como algo simplesmente dado, estagnado e independente, mas sim como completamente interligada e a relacionada com informações e características pertencentes ao contexto de sua produção, ao sujeito que a escreveu, e a diversos fatores que acabam por influenciar e fazer parte desta linguagem, compondo-a. Com base nisso, Rocha e Deusdará (2005, p. 319) reforçam: “A linguagem não se dissocia da interação social.”, ou seja, a interação social está presente no resultado, neste caso, nas produções jornalísticas que analisaremos neste trabalho.

Ora, é tendo como base esta ideia de que a linguagem não é deslocada de seu contexto e de influências externas que buscaremos compreender quais as formações discursivas presentes no discurso em análise. Aqui entendendo formação discursiva como:

uma região razoavelmente delimitada de sentidos que correspondem a uma determinada perspectiva ou ideologia (formação ideológica), e o sujeito se posiciona em um lugar para enunciar já inscrevendo os sentidos naquela formação discursiva (BENETTI, 2016, p. 240).

Estas formações discursivas podem, muitas vezes, serem supostas por nós em uma análise à priori do objeto de estudo, mas não é possível, sem a realização da análise de fato, que comprovemos estas suposições, afinal, o sujeito enunciador pode ou não se inscrever nas formações que consideramos prováveis a ele. Afinal também, Pêcheux (2014) apud Benetti (2016, p. 241) salienta que não apenas devemos compreender as formações discursivas presentes no objeto como independentes, mas que o sujeito que as enuncia e as características deste também adquirem sentido, de forma que (tomando o exemplo apresentado pelo autor), um padre católico defender a legalização do aborto produz sentidos diferentes de uma militante feminista defender o mesmo. Neste caso, a formação discursiva pode ser a mesma, mas apresenta e produz sentidos distintos.

Ainda, é com base na análise das formações discursivas presentes nos enunciados tomados como objeto que buscaremos perceber a presença de ideologias nestes discursos, considerando o que Pêcheux apud Benetti (2016, p. 319) coloca, evidenciando a "necessidade de perceber o ideológico como elemento constituinte da realidade linguística”. E, é claro, como já citado anteriormente será através do mapeamento de alguns sentidos produzidos pelo enunciado que realizaremos estas análises, afinal de acordo com Orlandi (2001), o analista de discurso precisa estar atento ao processo de produção de sentidos e aos próprios sentidos, 
afinal de contas o objetivo desta análise é revelar e descobrir os sentidos que ultrapassam o sistema linguístico.

Buscaremos então, ao longo do próximo tópico, desvelar alguns sentidos presentes no corpus de pesquisa, a fim de que saciemos nossos questionamentos aqui propostos. Para isso, destacaremos algumas sequências discursivas (SD), ou seja, partes do texto (sejam elas extensas ou mais curtas), que produzem significado e explicitam a opinião de algum sujeito (PÊCHEUX, 1997) que se mostram importantes e relevantes à nossa análise.

\subsection{Análises}

Como corpus da pesquisa temos duas matérias da mesma edição da revista Carta Capital, a primeira, "O monstro não é fascista", tem duas páginas e foi escrita por Mino Carta, enquanto a segunda, “Tod@s contra o capiroto", é mais extensa, com um total de cinco páginas e foi escrita por Fred Melo Paiva.

Apesar de tratarem de assuntos distintos acerca do então candidato e utilizarem-se de recursos distintos também, as duas matérias acabam por aproximar-se muito em relação aos sentidos que são produzidos por elas e às formações discursivas que se filiam.

Uma das principais redes de sentido que ambos os enunciados se filiam é a de resistência democrática, que podemos perceber, por exemplo, nas sequências discursivas a seguir:

SD1 - matéria 1: “[...] a devoção ao deus mercado e à definitiva substituição de qualquer aspiração democrática pelo regime do preconceito desbragado e da lei do mais forte"

SD1 - matéria 2: "A grande onda anti-bolsonaro liderada pelas mulheres envolve no caldo o bozo hospitalizado e pode ser fatal"

SD2 - matéria 2: "[...] o vírus antibolsonarista propaga-se poderosamente pelas redes. Brasil e mundo afora, de forma espontânea e apartidária"

Como se vê, nos dois textos é possível perceber que existe uma intenção de colocar em evidência as atividades antidemocráticas de Jair Bolsonaro e seus aliados e simpatizantes, mostrando e enfatizando então atitudes que reforcem e lutem pela democracia. Por mais que ao longo dos enunciados não seja utilizada diretamente a palavra "antidemocrático", os sentidos produzidos pelo texto ao falar a respeito destas atitudes, colocando-as como repudiáveis a todo o momento, faz com que esta fala direta não seja necessária e o sentido em questão fique implícito ao longo dos enunciados. 
Ambos os textos também trazem à tona uma memória discursiva em comum, que também está presente em diversas falas da mesma época e sobre o mesmo tema: o golpe de 1964 e o período ditatorial brasileiro vivido desse ano até 1985 no país:

SD2 - matéria 1: “A dita redemocratização esteve muito longe de justificar seu nome, a eleição de Lula, entretanto, criou ânimo novo por um tempo curto demais."

SD3 - matéria 1: "Poucos anos bastaram para nos mergulhar nesta situação de incerteza nunca dantes navegada."

SD3 - matéria 2: "[...] sugerindo a típica sessão de tortura."

SD4 - matéria 2: "Que as mulheres nos salvem das trevas."

Nos trechos acima, percebemos referências diretas e indiretas à época da ditadura militar brasileira, podendo despertar o sentimento de medo e apreensão. O acontecimento e a vivência da ditadura ainda são muito presentes na memória dos brasileiros e através de relações que ligam atitudes de Jair Bolsonaro com comportamentos típicos da ditadura militar no país, os enunciados produzem um sentido em comum: o de apreensão e nervosismo com base no pensamento de um possível retorno à ditadura apresentado indiretamente pelos textos. Ora, este sentimento produz, mesmo naqueles que embora contrários ao então candidato não pensavam em Jair Bolsonaro como uma ameaça à democracia, um sentimento de insegurança e de fragilidade de nosso modelo constitucional.

O posicionamento é um ponto muito claro nas matérias em análise, em ambas o então candidato Jair Bolsonaro é colocado como ameaçador e monstruoso. Ambos os enunciados tem como leitor imaginado (BENETTI, 2016) um sujeito posicionado à politicamente à esquerda, e a todo o tempo fala para este sujeito, sem questionar e sem a necessidade de um convencimento deste sujeito (afinal ele, ao menos virtualmente, já está convencido do que é posto ali), desta forma, acaba sendo conduzido, em ambos os casos analisados um discurso monofônico, onde aparecem apenas argumentos e informações contrários ao candidato.

Isto posto, alguns sentidos produzidos pela revista acerca de Jair Bolsonaro podem ser percebidos e elencados por nós. Começamos abordando que, como já falado anteriormente, a revista não trabalha com a antiga ideia de imparcialidade jornalística, ao contrário disto, ela traz de maneira clara seu posicionamento, colocando-se como frente de resistência ao então candidato. Podemos observar este comportamento nas seguintes sequências:

SD4 - matéria 1: "O monstro não é fascista"

SD5 - matéria 1: "Impossível comparar a Itália de 1922 com o Brasil de 2018 e Bolsonaro com Mussolini, mas aquele é tão terrificante quanto este"

SD6 - matéria 1: "[...] aqui o capitão explora a ignorância." 
SD7 - matéria 1: "O capitão Bolsonaro explora o caos provocado desde o impeachment de Dilma Rousseff para aprofundar até muito além da fronteira da demência os males do país da casa-grande e da senzala."

SD8 - matéria 1: "Somos vítimas de uma ignorância generalizada e o fenômeno Bolsonaro é de genuína extração nativa."

SD9 - matéria 1: "Bolsonaro promete um pesadelo terrificante"

SD5 - matéria 2: “[...] ao mesmo tempo em que ajudam a entender melhor o capetão, digo, capitão.”

SD6 - matéria 2: “[...] tem comido o pão que Bolsonaro amassou.”

SD7 - matéria 2: "Bom senso, esse o perigo, é artigo em falta entre bolsominions, que passaram a ameaçar a cantora e sua família.”

Como é possível perceber nas sequências apontadas acima, em ambas as matérias são trazidos sentidos que colocam Jair Bolsonaro, suas atitudes e seus apoiadores ligados a adjetivos pejorativos e negativos, colocando o então candidato como realmente alguém a ser combatido e, desta forma, explicitando sua ideologia, mesmo que não diga isso com todas as palavras. Nas sequências SD4-matéria 1 e SD5-matéria 2, percebemos a utilização de outros termos, que não o seu nome ou função, para denominar o político, chamando-o de "monstro" e "capetão", duas palavras negativas e que têm por objetivo desmerecer a imagem de Jair Bolsonaro.

Nos trechos SD5-matéria 1, SD7-matéria 1 e SD9-matéria 1, observamos que atitudes do militar da reserva são colocadas explicitamente como ameaçadoras e perigosas, unindo ao sentido de desprezo também o sentido de amedrontamento, coloca-o como um sujeito despreparado e ameaçador, e muitas vezes, principalmente ao longo da segunda matéria, utilizando para isso falas e ações de pessoas famosas e celebridades que comprovem o que está sendo dito.

Apesar de se utilizar, principalmente na primeira matéria analisada, de argumentos históricos, neste caso tendo como objetivo afastar a figura de Jair Bolsonaro do fascismo de Mussolini, isto não significa que a revista tenha por objetivo amenizar seus argumentos contrários a ele. Ao utilizar-se de elementos e fatos históricos, a revista reforça a ideia de credibilidade e legitimidade da informação, filiando-se a uma rede de sentido que aborda justamente essa ideia de argumentação histórica.

\section{Conclusões}


Observamos que, de acordo com as análises realizadas acima, nas duas publicações que compõem o corpus, os sentidos produzidos são muito semelhantes, de forma que é possível perceber uma padronização ao menos nesta edição da revista, o que acaba por refletir e possibilitar que compreendamos parte de sua identidade.

Ao não esconder seu posicionamento perante questões políticas e em nosso caso perante ao caso das eleições presidenciais de 2018 tendo como principal sujeito o militar da reserva Jair Bolsonaro, a revista não apenas nos possibilita a compreensão de que alinha-se à posicionamentos da esquerda política, mas, ao não procurar esconder seu posicionamento, mostra também um certo sentido de transparência que nos parece fazer parte de sua identidade.

Com o presente trabalho é possível que percebamos como se dá o comportamento da revista Carta Capital não apenas especificamente sobre Jair Bolsonaro, mas também nos permite perceber como se dá a conduta do veículo em relação as pautas políticas num geral, onde a revista coloca seu posicionamento abertamente nas pautas.

\section{Referências}

BENETTI, M. (2016). Análise de discurso como método de pesquisa em comunicação. MOURA, \& M. I. LOPES (org.), Pesquisa em comunicação: metodologias e práticas acadêmicas (pp. 235-256). Porto Alegre: EDIPUCRS.

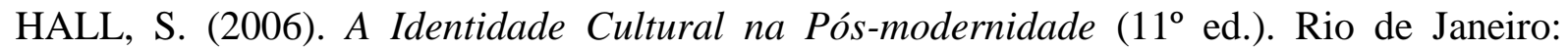
DP\&A.

ORLANDI, Eni. Discurso e texto. Campinas: Pontes, 2001.

PÊCHEUX, Michel. Semântica e Discurso: uma crítica à afirmação do óbvio. 3 ed. Campinas, SP: Editora da Unicamp, 1997.

ROCHA, D., \& DEUSDARÁ, B. (Julho - Dezembro de 2005). Análise de Conteúdo e Análise do Discurso: aproximações e afastamentos na (re)construção de uma trajetória. Alea, 305-322. 